\title{
The inhibitory effect of celecoxib and rosiglitazone on experimental endometriosis
}

\author{
Carla Olivares, M.Sc., Analía Ricci, M.Sc., Mariela Bilotas, Ph.D., Rosa Inés Barañao, Ph.D., \\ and Gabriela Meresman, Ph.D.
}

Instituto de Biología y Medicina Experimental (IBYME), CONICET, Ciudad Autónoma de Buenos Aires, Buenos Aires, Argentina

\begin{abstract}
Objective: To evaluate the effects of celecoxib and rosiglitazone on the implantation and growth of endometrioticlike lesions in a murine model of endometriosis.

Design: Prospective experimental study.

Setting: Animal research and laboratory facility.

Animal(s): Two-month-old female BALB/c mice.

Intervention(s): Surgically induced endometriosis in female BALB/C mice; 28 days of treatment with celecoxib, rosiglitazone, or their combination; counting, measuring, excising, and fixing lesions.

Main Outcome Measure(s): Immunohistochemical examination for proliferating cell nuclear antigen (PCNA), CD31, and CD34 to assess cell proliferation and vascularization, with the terminal deoxynucleotidyl transferase dUTP nick end labeling (TUNEL) technique for apoptosis evaluation.

Result(s): Celecoxib and the combined treatment (celecoxib and rosiglitazone) statistically significantly reduced the mean number of lesions established per mouse, and all treatments diminished the implant volume. In addition, cell proliferation within the implants was statistically significantly reduced, and apoptosis was statistically significantly enhanced by all treatments. Also, we found that all treatments diminished the vascularized area in the lesion. Conclusion(s): These results are promising and reveal that celecoxib and rosiglitazone, combined or separately, have a beneficial effect on overall endometriotic growth. (Fertil Steril ${ }^{\circledR}$ 2011;96:428-33. C2011 by American Society for Reproductive Medicine.)
\end{abstract}

Key Words: Apoptosis, cell proliferation, COX-2 inhibitor, endometriosis, PPAR $\gamma$ agonist

Endometriosis, a common benign gynecologic disease characterized by the presence and proliferation of endometrial tissue outside the uterine cavity, affects women of reproductive age (1). Because endometriosis is an estrogen-dependent disease, the treatment options aim at maintaining a hypoestrogenic environment, which removes the opportunity for conception from women who are under treatment (2). Furthermore, the therapy's side effects limit its long-term use, and endometriosis recurrence after cessation of therapy is not uncommon (3). Therefore, developing better treatment options for patients with endometriosis is necessary.

In the past few years, COX-2, the inducible form of cyclooxygenase, has gained special attention. This enzyme, which is involved in inflammatory processes, has been demonstrated to be overexpressed in several pathologic conditions, including endometriosis (4-6). Selective COX-2 inhibitors are a special class of non-steroidal anti-inflammatory drugs (NSAIDs) that were developed to treat pain and inflammation without inhibiting COX-1 while sparing the gastrointestinal system. In previous studies, we added a selective COX-2 inhibitor to cultured epithelial endometrial human cells and

Received April 11, 2011; revised May 18, 2011; accepted May 19, 2011; published online June 20, 2011.

C.O. has nothing to disclose. A.R. has nothing to disclose. M.B. has nothing to disclose. R.I.B. has nothing to disclose. G.M. has nothing to disclose.

Supported by ANPCYT (PICT 6384 BID 1201 OC-AR), CONICET (PIP 5471) and Fundación Roemmers, Buenos Aires, Argentina.

Reprint requests: Carla Olivares, M.Sc., Instituto de Biología y Medicina Experimental (IBYME), CONICET, Vuelta de Obligado 2490, (C1428ADN) Ciudad Autónoma de Buenos Aires, Argentina (E-mail: carla.olivares@ibyme.conicet.gov.ar). found that it inhibited cell proliferation, enhanced cell apoptosis, and diminished vascular endothelial growth factor (VEGF) and prostaglandin (PG) $\mathrm{E}_{2}$ secretion (7). These drugs have also been used in endometriosis animal models and have been demonstrated to prevent the implantation of endometrium to ectopic sites (8) and to induce the regression of endometrial explants in mice (9) and rats (10).

Peroxisome proliferator-activated receptors (PPARs) are a family of nuclear receptors that respond to endogenous ligands and chemical compounds modulating the transcription of a large number of genes (11). Three classes of PPARs have been described so far: $\operatorname{PPAR} \alpha, \operatorname{PPAR} \beta / \delta$, and $\operatorname{PPAR} \gamma(12)$.

It has been previously described that $15 \mathrm{~d}-\mathrm{PGJ}_{2}$ is the natural ligand of PPAR $\gamma$ (13); the thiazolidinediones (TZDs), currently used as antidiabetic drugs, are its synthetic ligands (14). It has been reported that TZDs inhibit tumor growth both in vitro and in vivo (15-17). Panigrahy et al. (17) demonstrated that the inhibition by PPAR $\gamma$ ligands of tumor growth was mediated by inhibiting endothelial cell proliferation, thus diminishing angiogenesis within the tumor; some TZDs have been found to be anti-inflammatory agents (18). It has also been shown that at high concentrations COX-2 inhibitors can also act as PPAR $\gamma$ agonists (19).

Combining the activation of PPAR $\gamma$ with the inhibition of COX-2 appears to be a promising strategy in cancer. It was demonstrated that combined treatment with celecoxib and F-L-Leu, a PPAR $\gamma$ agonist, retards the appearance of tumors in a model of spontaneous breast cancer (20). More recently, similar results were obtained in a human pancreatic cell carcinoma model (21). In endometriosis, one study has targeted PPAR $\gamma$ simultaneously with another molecule, retinoid X receptor ( $R X R$ ), in immortalized endometrial stromal cells, achieving a synergistic inhibition of cell proliferation (22). However, 
to our knowledge, the effects of a COX-2 inhibitor in combination with a PPAR $\gamma$ ligand in an endometriosis model have not yet been studied.

We examined the efficacy of celecoxib, a potent COX-2 inhibitor, and rosiglitazone, a PPAR $\gamma$ ligand, separately and in combination, on the establishment and growth of endometriotic-like lesions in a murine model of endometriosis. In addition, we evaluated cell proliferation and apoptosis in the epithelial cells of the endometriotic implants as well as their vascularization.

\section{MATERIALS AND METHODS Animals}

In this study, 48 2-month-old female BALB/c mice were used. All procedures were performed according to U.S. National Institutes of Health Guidelines for the Care and Use of Laboratory Animals and were approved by the Ethics and Research Committee from IBYME, Buenos Aires, Argentina. A total of seven animals died or had to be sacrificed between 2 to 3 days after surgery because they did not fully recover from the intervention.

\section{Surgical Induction of Endometriosis and Treatment}

Endometriosis-like lesions were induced through transplantation of one of the uterine horns to the bowel mesentery, as previously described elsewhere $(23,24)$. Briefly, the animals were deeply anesthetized with an intraperitoneal injection of ketamine $(100 \mathrm{mg} / \mathrm{kg})$ and xylazine $(10 \mathrm{mg} / \mathrm{kg})$. The mice underwent laparotomy by midventral incision to expose the uterus and intestine. The right uterine horn was removed, opened longitudinally, and cut into square pieces that measured approximately $4 \mathrm{~mm}^{2}$. Three equal pieces of tissue were then sutured onto the serosal layer with a single 6-0 nylon suture (Supralon; Ethicon) with endometrial tissue facing the serosa. The abdomen was then closed with a 5-0 nylon suture.

The animals were assigned to four different treatment groups: control (100 $\mu \mathrm{L}$ distilled water with $0.5 \%$ carboxymethylcellulose [CMC]); celecoxib $(200 \mathrm{mg} / \mathrm{kg}$ in water with $0.5 \% \mathrm{CMC}$ ) (Pfizer); rosiglitazone $(0.16 \mathrm{mg} / \mathrm{kg}$ ) (Montpellier); or celecoxib + rosiglitazone with the drugs combined. The dosages in this study were chosen based on other in vivo reports $(25,26)$. The rosiglitazone dosage used is similar to that used by type 2 diabetes patients ( 4 or $8 \mathrm{mg}$ daily), whereas the dosage of celecoxib is higher than that used in cancer patients $(800 \mathrm{mg}$ daily). All treatments were administered daily by esophageal gavage, starting on postoperative day 1 and continuing for 28 days. No evidence of toxicity was noted at the doses administered based on body weight, food consumption, grooming behavior, or activity levels compared with controls.

\section{Evaluation of Endometriotic-Like Lesions}

After 4 weeks of treatment, the animals were killed by cervical dislocation. The abdomen was opened by ventral midline incision. Implantation sites were localized by the presence of a lesion or by suture alone. Lesions were counted and measured for volume determination by use of the following formula: $V=(4 / 3) \pi r 2 R$ (where $V$ is volume, and $r$ and $R$ are the radiuses, $r<R$ ) (27). Then lesions were excised, fixed, and embedded in paraffin. The specimens were cut into $5-\mu \mathrm{m}$ serial sections. Four to five noncontiguous sections from each specimen were stained with hematoxylin and eosin and were examined microscopically for the presence of the histologic hallmarks (glands and stroma) of endometriosis.

\section{Immunohistochemistry for PCNA, CD31, and CD34}

Serial sections of endometriotic lesions were subjected to standard immunohistochemical analysis. Tissue sections were incubated overnight with the primary antibody (rabbit anti-mouse proliferating cell nuclear antigen [PCNA] polyclonal, 1:300, FL-261; Santa Cruz Biotechnology; rat antimouse CD31 monoclonal, 1:50, ab56299; Abcam; or rat anti-mouse CD34 monoclonal, 1:50, ab8158; Abcam) at $4{ }^{\circ} \mathrm{C}$. After that, sections were treated for 60 minutes with the corresponding secondary biotinylated antibody (antirabbit IgG, 1:200, B7389; Sigma-Aldrich; or goat anti-rat IgG, 1:500, B7139; Sigma-Aldrich) followed by incubation with streptavidin-peroxidase (LSAB + System; Dako). The binding was visualized by incubating sections with diaminobenzidine (DAB) and lightly counterstaining with hematoxylin before permanent mounting.

The number of cells expressing immunoreactivity for PCNA was established using a standard light microscope. A total of 300 epithelial cells were counted, and the percentage of PCNA positive cells was calculated. Any nuclear staining was regarded as positive.

Ten fields for each slide containing all lesions were analyzed with ImageJ version $1.33 \mathrm{u}$ software (http://rsbweb.nih.gov/ij) for determining the percentage of the vascularized area. The positive stain for CD31 or CD34 was calculated per field and averaged per mouse. Then all averages were used to obtain the mean vascularized area per treatment group.

\section{FIGURE 1}

Effect of celecoxib and rosiglitazone on endometriotic-like lesion establishment and growth. Mice underwent surgery for endometriosis induction. After 28 days of treatment with vehicle, celecoxib, rosiglitazone, or both drugs simultaneously, the mice were sacrificed, and the number of lesions established was counted and measured. (A) Celecoxib and the combined treatment (Cele + Rosi) statistically significantly reduced the mean number of lesions established per mouse. (B) Celecoxib and rosiglitazone, separately, and the combined therapy (Cele + Rosi) statistically significantly reduced implant size. Results are expressed as mean \pm standard error of the mean. ${ }^{\star} P<.05$ versus control group. ${ }^{\star \star \star} P<.001$ versus control group. $\mathrm{n}=11$ (control), 12 (celecoxib), 8 (rosiglitazone), 10 (Cele + Rosi).
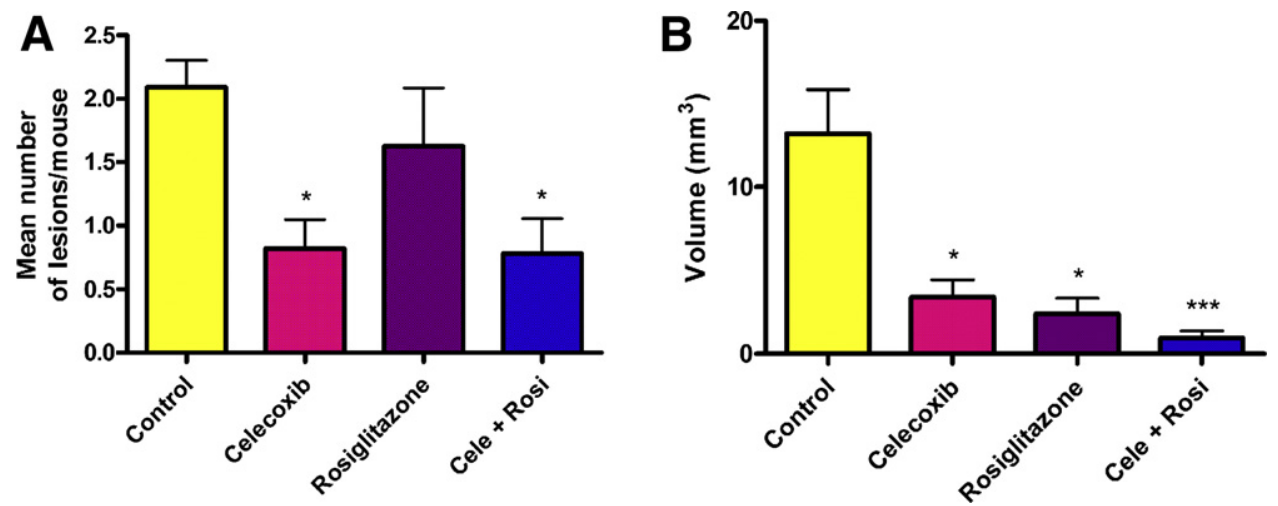

Olivares. COX-2 and PPAR $\gamma$ in endometriosis. Fertil Steril 2011. 


\section{TUNEL Assay}

For apoptosis quantification, sections were processed for in situ immunohistochemical localization of nuclei exhibiting DNA fragmentation by use of the apoptosis detection kit Apoptag Plus (Chemicon International). Sections were treated according to the manufacturer's instructions as previously described elsewhere (28). The number of cells positive for terminal deoxynucleotidyl transferase dUTP nick end labeling (TUNEL) stain was established by use of a standard light microscope at $\times 400$ magnification. A total of 300 epithelial cells were counted, and the percentage of TUNEL positive cells was calculated.

\section{Statistical Analysis}

Statistical analyses were performed using GraphPad Instat version 4.0 software (Windows version; GraphPad Software). Statistical comparisons between groups were performed by use of parametric analysis of variance (ANOVA) with Tukey's multiple comparison post test or nonparametric ANOVA with Dunn's multiple comparison post test. Results were expressed as mean \pm standard error of the mean (SEM). $P<.05$ was considered statistically significant.

\section{RESULTS}

\section{Effect of Celecoxib and Rosiglitazone on Endometriotic- Like Lesion Establishment and Size}

The group treated only with celecoxib and the group receiving the combined therapy had a statistically significant reduction in the number of established lesions per animal ( $P<.05$ vs. control group). The results are displayed in Figure 1A.

Regarding the volume of developed lesions, all treatment groups had a statistically significant reduction in lesion size. As seen in Figure 1B, although there is not a statistically significant difference between the treated groups, celecoxib and rosiglitazone combined tended to be more efficient in reducing the lesion volume $(P<.001$ vs. control group) than either of the treatments alone.

\section{Celecoxib and Rosiglitazone Treatments Affect Cell Proliferation and Apoptosis in Endometriotic-Like Lesions}

All treatment groups had diminished cell proliferation compared with the control group (rosiglitazone-only and celecoxib + rosiglitazone groups, $P<.001$ vs. control; celecoxib-only group, $P<.01$ vs. control). The results are displayed in Figure 2. The combined treatment appeared to be slightly more effective in decreasing cell proliferation than either of the drugs separately, but the effect was not synergistic nor additive.

All treatments were effective enhancing apoptosis compared with the control group $(P<.05)$, as seen in Figure 3 . Not only did the TUNEL assay demonstrate that apoptosis was augmented in the treatment groups, but also the regression of the lesions was clearly visible in the histologic analysis of the sections (data not shown).

\section{Inhibiting COX-2 and Activating PPAR $\gamma$ Decrease Vascular Density in Endometriotic-Like Lesions}

Figure 4 shows the effect of the treatments on vascular density as assessed by CD31 and CD34 immunohistochemistry. As observed with CD31 staining, rosiglitazone-only and the combined treatment resulted in a statistically significant reduction of vascular density $(P<.05$ vs. control group). When the same parameter was evaluated via immunostaining with CD34, the celecoxib-only and rosiglitazone-only groups showed a statistically significant decrease in vascular density when compared with the control group $(P<.05)$; even though there was no statistically significant difference between the treated groups, when the treatments were administered in combination the reduction tended to be superior $(P<.01 \mathrm{vs}$. control group).

\section{FIGURE 2}

Effect of celecoxib and rosiglitazone on endometriotic-like lesion epithelial cell proliferation. Mice underwent surgery for endometriosis induction. After 28 days of treatment with vehicle, celecoxib, rosiglitazone, or both drugs simultaneously, the mice were sacrificed, and the implants were removed and fixed. Cell proliferation within the implants was evaluated by immunohistochemistry of proliferating cell nuclear antigen (PCNA). (A) After treatment with celecoxib, rosiglitazone, or both drugs simultaneously (Cele + Rosi), epithelial cell proliferation was statistically significantly diminished compared with control mice. Results are expressed as mean \pm standard error of the mean. ${ }^{\star \star} P<.01$ versus control group; ${ }^{\star \star \star} P<.001$ versus control group. (B) Representative photographs of PCNA staining. Control group (i), celecoxib group (ii), rosiglitazone group (iii), celecoxib + rosiglitazone group (iv). Inset: negative control, an immunoglobulin of the same immunoglobulin class and concentration as the primary antibody was used. Magnification $\times 400 . n=8$ (control), 7 (celecoxib), 5 (rosiglitazone), 5 (Cele + Rosi).
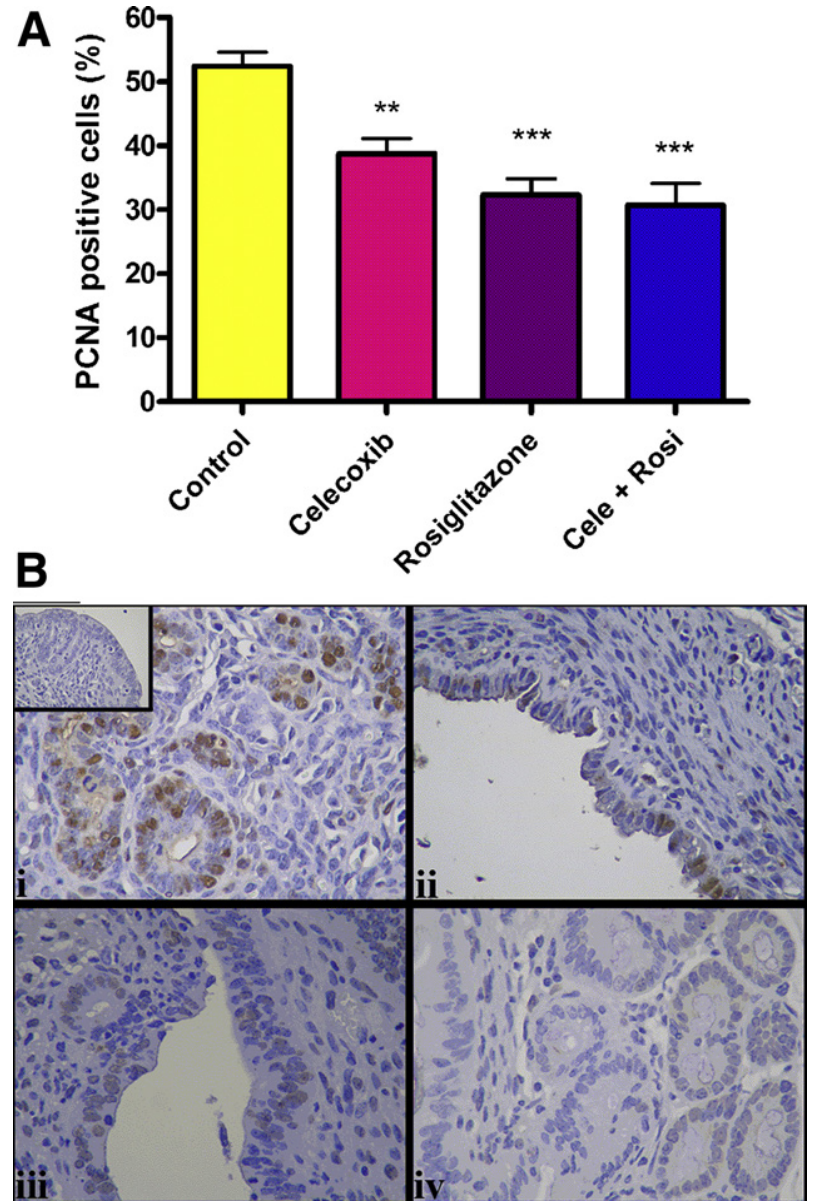

Olivares. COX-2 and PPAR $\gamma$ in endometriosis. Fertil Steril 2011.

\section{DISCUSSION}

The current medical treatment of endometriosis is still associated with a high recurrence rate. The therapeutic options include surgery and hormone therapy; which are often temporarily effective but produce unwanted side effects $(2,29,30)$. Given this scenario, it is of great importance to study new strategies to treat endometriosis that minimize the adverse effects and reduce the rates of recurrence. 


\section{FIGURE 3}

Effect of celecoxib and rosiglitazone on endometriotic-like lesion epithelial cell apoptosis. Mice underwent surgery for endometriosis induction. After 28 days of treatment with vehicle, celecoxib, rosiglitazone, or both drugs simultaneously, the mice were sacrificed, and the implants were removed and fixed. Apoptosis within the implants was evaluated by TUNEL assay. (A) After treatment with celecoxib, rosiglitazone, or both drugs simultaneously (Cele + Rosi), epithelial cell apoptosis was enhanced compared with the control group. Results are expressed as mean \pm standard error of the mean. ${ }^{\star} P<.05$ versus control group. (B) Representative photographs of TUNEL staining. Control group (i), celecoxib group (ii), rosiglitazone group (iii), celecoxib + rosiglitazone group (iv). Inset: negative control, sections were incubated in absence of TdT. Magnification $\times 400$. $\mathrm{n}=6$ (control), 7 (celecoxib), 5 (rosiglitazone), 5 (Cele + Rosi).
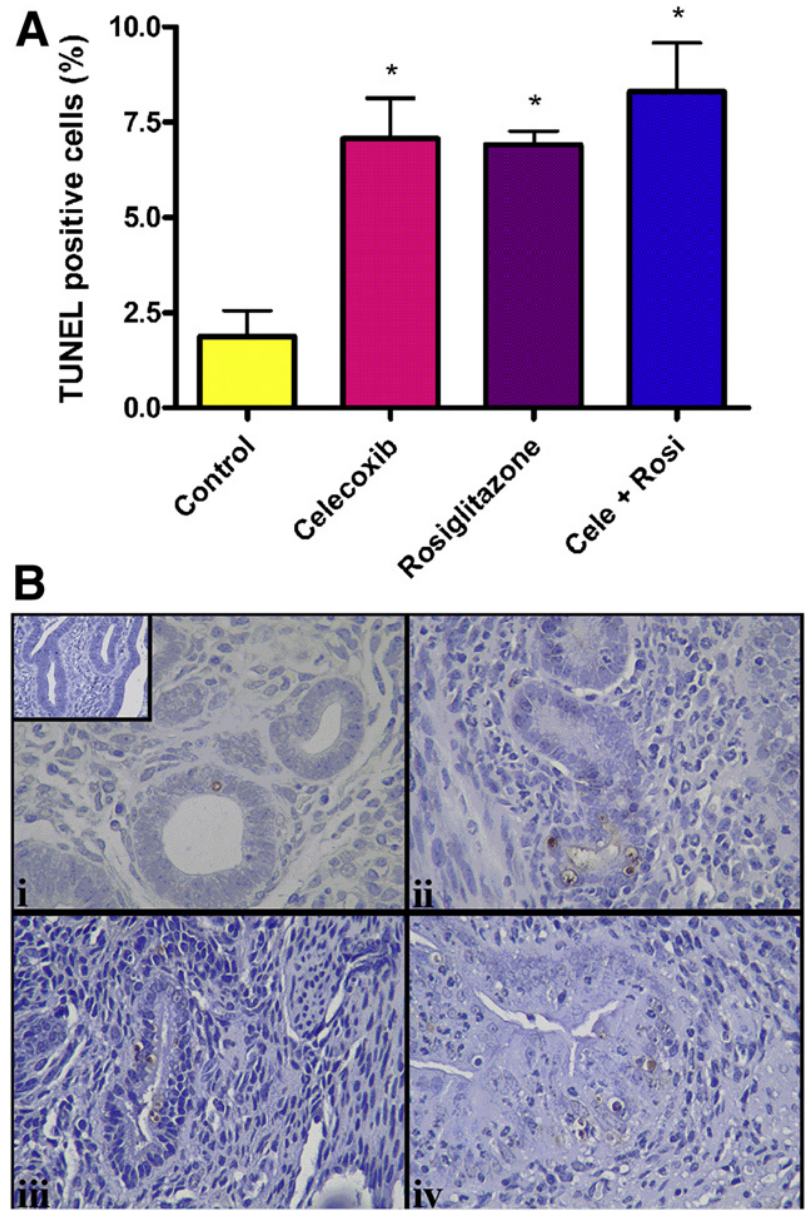

Olivares. COX-2 and PPAR in endometriosis. Fertil Steril 2011.

In our study, we found that celecoxib treatment inhibited endometriotic-like lesion establishment and growth. To clarify the mechanisms involved in this inhibition, we assessed cell proliferation, apoptosis, and vascular density after administration of celecoxib. Cell proliferation within the lesions was diminished compared with control mice, as was the vascular density. In addition, apoptosis was augmented in the endometriosis-like lesions.

Consistent data have suggested that COX-2 inhibitors can reduce cancer risk in patients, prevent tumorigenesis, and suppress established tumor growth in animals (31). In various in vivo and in vitro cancer models, COX-2 inhibitors have proven to have antiproliferative, proapoptotic, and antiangiogenic activity (32-35). It has been previously described that $\mathrm{COX}-2$ is overexpressed in the eutopic and ectopic endometrium of women with endometriosis compared with controls $(5,6)$, and the effects of inhibiting this enzyme in several endometriosis models have been studied $(7,9,10)$. The modern selective COX-2 inhibitors have not yet been approved for use in endometriosis. However, a first promising placebo-controlled, double-blind study showed that the use of a COX-2-inhibitor was an effective, safe, and inexpensive therapeutic approach to endometriosis-associated pelvic pain (36).

In our study, we also found that rosiglitazone treatment inhibited endometriotic implant growth. Moreover, we studied the levels of apoptosis, cell proliferation, and vascularization within the endometriotic-like lesions and found that apoptosis after rosiglitazone treatment was augmented compared with controls, whereas cell proliferation and vascularization were inhibited. However, with rosiglitazone treatment alone we did not observe a reduction of endometriotic-like lesion development, as opposed to celecoxib alone or the combined treatment. We believe that this phenomenon might be due to celecoxib's more potent effect over rosiglitazone, when administered during this period of time and at the dose evaluated, on the growth of the endometriotic-like lesions. This would eventually translate into a reduced number of endometriotic-like lesions developing.

PPARs have been described in a variety of tissues, including reproductive tissues. In breast cancer, PPAR $\gamma$ has received focused attention because it was seen to be inactivated (37) and to mediate antitumor effects after activation by TZDs (38). In different in vivo rodent models, beneficial effects after treatment with TZDs have been described, including inhibition of tumor growth, enhancement of tumor apoptosis, and overall survival rate $(16,17)$.

In endometriosis, PPAR $\gamma$ ligands have also been used with promising results both in vitro and in vivo. Ciglitazone reduced the size of experimentally induced endometriotic lesions in a rat model of endometriosis (39), and rosiglitazone was effective at reducing endometriotic growth and causing regression of established implants in a similar animal model $(40,41)$. More recently, a study done on baboons evaluated the effects of rosiglitazone versus a gonadotropin-releasing hormone $(\mathrm{GnRH})$ antagonist and observed that the TZD provoked implant regression $(42,43)$. Pioglitazone has also been described as effective in reducing adhesions in a chimeric mouse model of endometriosis (44).

In endometriosis treatment, an overall beneficial effect has been reported after administration of rosiglitazone in a reduced number of patients with endometriosis, including ameliorating endometriosis symptoms and pain (45). It is noteworthy that rosiglitazone not only does not impede ovulation (45) but also has been reported to help restore spontaneous ovulation (46), an improvement over current medical therapies for endometriosis (45). In addition, it has been reported that rosiglitazone does not cause any alteration to the mouse fetus when administered during pregnancy (25). Rosiglitazone is daily taken by type 2 diabetes patients; although it is an approved drug by the U.S. Food and Drug Administration (FDA), its safety is being questioned because of potential cardiac risks. Pioglitazone, another TZD used in the treatment of type 2 diabetes, has FDA warnings on its use as well. Several studies that have evaluated rosiglitazone's cardiovascular safety, included elderly diabetes patients with high cardiovascular risk, and when compared to pioglitazone, it seems safer than rosiglitazone $(47,48)$, but the matter is still controversial (49-51). 
Effect of celecoxib and rosiglitazone on endometriotic-like lesion vascular density. Mice underwent surgery for endometriosis induction. After 28 days of treatment with vehicle, celecoxib, rosiglitazone, or both drugs simultaneously, the mice were sacrificed, and the implants were removed and fixed. Vascular density within the implants was evaluated by performing immunohistochemical analysis of CD31 and CD34. (A) CD31: After treatment with rosiglitazone and both drugs simultaneously (Cele + Rosi), the vascular density was diminished compared with control mice. (B) CD34: After treatment with celecoxib, rosiglitazone, or both drugs simultaneously (Cele + Rosi), the vascular density was diminished compared with control mice. Results are expressed as mean \pm standard error of the mean. ${ }^{\star} P<.05$ versus control group; ${ }^{\star \star} P<.01$ versus control group. $n=5$ (control), 5 (celecoxib), 5 (rosiglitazone), 5 (Cele + Rosi).
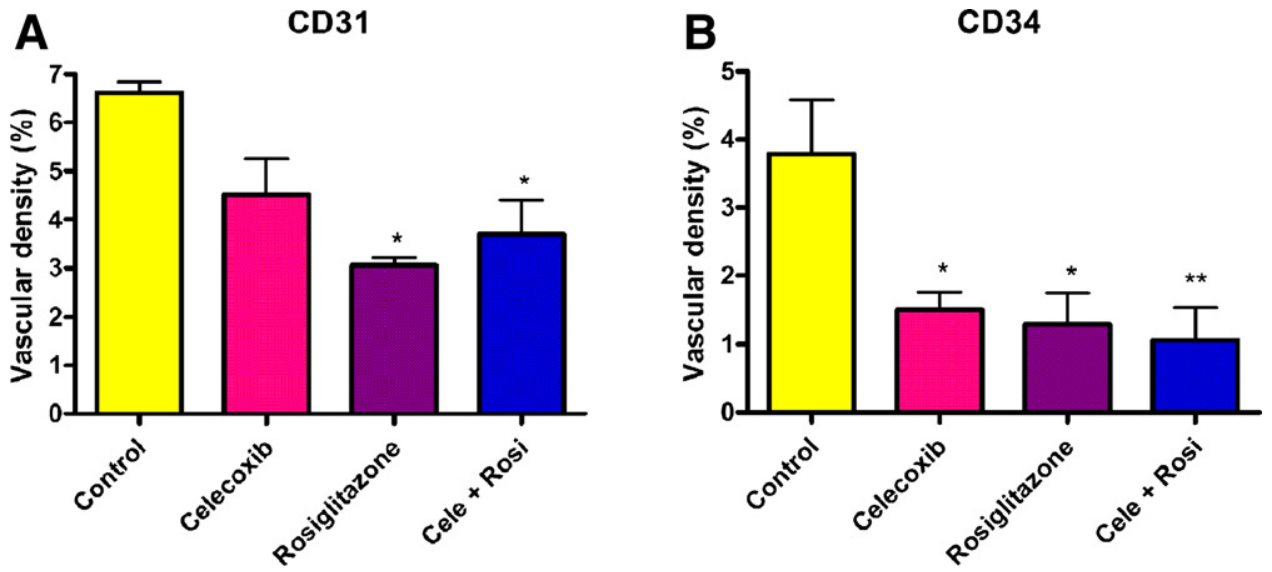

Olivares. COX-2 and PPAR in endometriosis. Fertil Steril 2011.

The studies published on combination therapy with COX-2 inhibitors and PPAR $\gamma$ activators are mainly focused in cancer models. Both in vivo and in vitro, this treatment has accomplished beneficial results, inhibiting cell proliferation, enhancing apoptosis (21), and even increasing the overall survival rate (20).

To the best of our knowledge, ours is the first study to use combination therapy targeting PPAR $\gamma$ and COX-2 in an in vivo endometriosis model. This study reveals that the targeting of these molecules simultaneously has good effects on endometriotic implantation and growth, and the combination tends to show improvement over focusing on either of them alone. We conclude that the reduction in cell proliferation and vascular density and the increase in the apoptosis rate are mechanisms implicated in this effect. The reduction in the number of lesions developed, we believe, is mostly an effect of celecoxib, as with celecoxib treatment alone they developed similarly to the combination therapy.

The results presented are promising, and it is encouraging that the drugs used in this study, combined or separately, are currently being used for the treatment of other illnesses. Nevertheless, further research is necessary to ascertain whether this combination therapy is appropriate for the treatment of endometriosis.

\section{REFERENCES}

1. Crosignani P, Olive D, Bergqvist A, Luciano A. Advances in the management of endometriosis: an update for clinicians. Hum Reprod Update 2006;12:179-89.

2. de Ziegler D, Borghese B, Chapron C. Endometriosis and infertility: pathophysiology and management. Lancet 2010;376:730-8.

3. Valle RF, Sciarra JJ. Endometriosis: treatment strategies. Ann NY Acad Sci 2003;997:229-39.

4. $\mathrm{Wu} \mathrm{MH}, \mathrm{Lu} \mathrm{CW}$, Chuang PC, Tsai SJ. Prostaglandin E2: the master of endometriosis? Exp Biol Med (Maywood) 2010;235:668-77.

5. Matsuzaki S, Canis M, Pouly JL, Wattiez A, Okamura K, Mage G. Cyclooxygenase-2 expression in deep endometriosis and matched eutopic endometrium. Fertil Steril 2004;82:1309-15.

6. Ota H, Igarashi S, Sasaki M, Tanaka T. Distribution of cyclooxygenase- 2 in eutopic and ectopic endometrium in endometriosis and adenomyosis. Hum Reprod 2001;16:561-6.

7. Olivares C, Bilotas M, Buquet R, Borghi M, Sueldo $\mathrm{C}$, Tesone $\mathrm{M}$, et al. Effects of a selective cyclooxygenase-2 inhibitor on endometrial epithelial cells from patients with endometriosis. Hum Reprod 2008;23:2701-8.
8. Matsuzaki S, Canis M, Darcha C, Dallel R, Okamura K, Mage G. Cyclooxygenase-2 selective inhibitor prevents implantation of eutopic endometrium to ectopic sites in rats. Fertil Steril 2004;82:1609-15.

9. Ozawa Y, Murakami T, Tamura M, Terada Y, Yaegashi N, Okamura K. A selective cyclooxygenase-2 inhibitor suppresses the growth of endometriosis xenografts via antiangiogenic activity in severe combined immunodeficiency mice. Fertil Steril 2006;86(Suppl 4):1146-51.

10. Dogan E, Saygili U, Posaci C, Tuna B, Caliskan S, Altunyurt $\mathrm{S}$, et al. Regression of endometrial explants in rats treated with the cyclooxygenase- 2 inhibitor rofecoxib. Fertil Steril 2004;82(Suppl 3):1115-20.

11. Eibl G, Reber HA, Hines OJ, Go VL. COX and PPAR: possible interactions in pancreatic cancer. Pancreas 2004;29:247-53.

12. Biscetti F, Straface G, Pitocco D, Zaccardi F, Ghirlanda G, Flex A. Peroxisome proliferatoractivated receptors and angiogenesis. Nutr Metab Cardiovasc Dis 2009;19:751-9.

13. Straus DS, Glass CK. Cyclopentenone prostaglandins: new insights on biological activities and cellular targets. Med Res Rev 2001;21:185-210.
14. Staels B, Fruchart JC. Therapeutic roles of peroxisome proliferator-activated receptor agonists. Diabetes 2005;54:2460-70.

15. Magenta G, Borenstein X, Rolando R, Jasnis MA. Rosiglitazone inhibits metastasis development of a murine mammary tumor cell line LMM3. BMC Cancer 2008;8:47-57.

16. Kim SW, Choi OK, Chang MS, Shin CS, Park KS, Kim SY. Thiazolidinediones inhibit the growth of PC12 cells both in vitro and in vivo. Biochem Biophys Res Commun 2008;371:197-202.

17. Panigrahy D, Singer S, Shen LQ, Butterfield CE, Freedman DA, Chen EJ, et al. PPAR $\gamma$ ligands inhibit primary tumor growth and metastasis by inhibiting angiogenesis. J Clin Invest 2002;110:923-32.

18. Hazra S, Peebles KA, Sharma S, Mao JT, Dubinett SM. The role of PPAR $\gamma$ in the cyclooxygenase pathway in lung cancer. PPAR Res 2008;2008: 790568.

19. Eibl G. The role of PPAR-gamma and its interaction with COX-2 in pancreatic cancer. PPAR Res 2008;2008:326915.

20. Mustafa A, Kruger WD. Suppression of tumor formation by a cyclooxygenase- 2 inhibitor and 
a peroxisome proliferator-activated receptor gamma agonist in an in vivo mouse model of spontaneous breast cancer. Clin Cancer Res 2008;14:4935-42.

21. Sun WH, Chen GS, Ou XL, Yang Y, Luo C, Zhang Y, et al. Inhibition of COX-2 and activation of peroxisome proliferator-activated receptor gamma synergistically inhibits proliferation and induces apoptosis of human pancreatic carcinoma cells. Cancer Lett 2009;275:247-55.

22. Wu Y, Guo SW. Peroxisome proliferator-activated receptor-gamma and retinoid $\mathrm{X}$ receptor agonists synergistically suppress proliferation of immortalized endometrial stromal cells. Fertil Steril 2009;91:2142-7.

23. Ricci AG, Olivares CN, Bilotas MA, Meresman GF, Baranao RI. Effect of vascular endothelial growth factor inhibition on endometrial implant development in a murine model of endometriosis. Reprod Sci. Published online January 25, 2011.

24. Bilotas M, Meresman G, Stella I, Sueldo C, Baranao RI. Effect of aromatase inhibitors on ectopic endometrial growth and peritoneal environment in a mouse model of endometriosis. Fertil Steril 2010;93:2513-8.

25. Klinkner DB, Lim HJ, Strawn EY Jr, Oldham KT, Sander TL. An in vivo murine model of rosiglitazone use in pregnancy. Fertil Steril 2006;86:1074-9.

26. Peluffo GD, Stillitani I, Rodriguez VA, Diament MJ, Klein SM. Reduction of tumor progression and paraneoplastic syndrome development in murine lung adenocarcinoma by nonsteroidal antiinflammatory drugs. Int J Cancer 2004;110:825-30.

27. Brodie A, Jelovac D, Long BJ. Predictions from a preclinical model: studies of aromatase inhibitors and antiestrogens. Clin Cancer Res 2003;9:S455-9.

28. Meresman GF, Vighi S, Buquet RA, Contreras-Ortiz O, Tesone M, Rumi LS. Apoptosis and expression of Bcl-2 and Bax in eutopic endometrium from women with endometriosis. Fertil Steril 2000;74:760-6.

29. Mihalyi A, Simsa P, Mutinda KC, Meuleman C, Mwenda JM, D'Hooghe TM. Emerging drugs in endometriosis. Expert Opin Emerg Drugs 2006;11:503-24.

30. Rice VM. Conventional medical therapies for endometriosis. Ann NY Acad Sci 2002;955:343-52.

31. Bundred NJ, Barnes NL. Potential use of COX2 -aromatase inhibitor combinations in breast cancer. Br J Cancer 2005;93(Suppl 1):S10-5.
32. Grosch S, Maier TJ, Schiffmann S, Geisslinger G. Cyclooxygenase-2 (COX-2)-independent anticarcinogenic effects of selective COX-2 inhibitors. J Natl Cancer Inst 2006;98:736-47.

33. Basu GD, Pathangey LB, Tinder TL, Gendler SJ, Mukherjee P. Mechanisms underlying the growth inhibitory effects of the cyclo-oxygenase- 2 inhibitor celecoxib in human breast cancer cells. Breast Cancer Res 2005; 7:R422-35.

34. Leahy KM, Ornberg RL, Wang Y, Zweifel BS, Koki AT, Masferrer JL. Cyclooxygenase-2 inhibition by celecoxib reduces proliferation and induces apoptosis in angiogenic endothelial cells in vivo. Cancer Res 2002;62:625-31.

35. Elder DJ, Halton DE, Crew TE, Paraskeva C. Apoptosis induction and cyclooxygenase- 2 regulation in human colorectal adenoma and carcinoma cell lines by the cyclooxygenase-2-selective non-steroidal anti-inflammatory drug NS-398. Int J Cancer 2000;86:553-60.

36. Cobellis L, Razzi S, De Simone S, Sartini A, Fava A, Danero S, et al. The treatment with a COX-2 specific inhibitor is effective in the management of pain related to endometriosis. Eur J Obstet Gynecol Reprod Biol 2004;116:100-2.

37. Badawi AF, Badr MZ. Expression of cyclooxygenase-2 and peroxisome proliferatoractivated receptor-gamma and levels of prostaglandin $\mathrm{E} 2$ and 15-deoxy- $\delta 12,14$-prostaglandin $\mathrm{J} 2$ in human breast cancer and metastasis. Int $\mathrm{J}$ Cancer 2003;103:84-90.

38. Blanquicett C, Roman J, Hart CM. Thiazolidinediones as anti-cancer agents. Cancer Ther 2008;6:25-34.

39. Lebovic DI, Kir M, Casey CL. Peroxisome proliferator-activated receptor-gamma induces regression of endometrial explants in a rat model of endometriosis. Fertil Steril 2004;82(Suppl 3):1008-13.

40. Aytan H, Caliskan AC, Demirturk F, Aytan P, Koseoglu DR. Peroxisome proliferator-activated receptor-gamma agonist rosiglitazone reduces the size of experimental endometriosis in the rat model. Aust NZ J Obstet Gynaecol 2007;47:321-5.

41. Demirturk F, Aytan H, Caliskan AC, Aytan P, Koseoglu DR. Effect of peroxisome proliferatoractivated receptor-gamma agonist rosiglitazone on the induction of endometriosis in an experimental rat model. J Soc Gynecol Investig 2006;13:58-62.
42. Lebovic DI, Mwenda JM, Chai DC, Santi A, Xu X, D'Hooghe T. Peroxisome proliferator-activated receptor- $\gamma$ receptor ligand partially prevents the development of endometrial explants in baboons: a prospective, randomized, placebo-controlled study. Endocrinology 2010;151:1846-52.

43. Lebovic DI, Mwenda JM, Chai DC, Mueller MD, Santi A, Fisseha S, et al. PPAR-gamma receptor ligand induces regression of endometrial explants in baboons: a prospective, randomized, placebo- and drug-controlled study. Fertil Steril 2007;88:1108-19.

44. Herington JL, Crispens MA, Carvalho-Macedo AC, Camargos AF, Lebovic DI, Bruner-Tran KL, et al. Development and prevention of postsurgical adhesions in a chimeric mouse model of experimental endometriosis. Fertil Steril 2011;95:1295-301.

45. Moravek MB, Ward EA, Lebovic DI. Thiazolidinediones as therapy for endometriosis: a case series. Gynecol Obstet Invest 2009;68:167-70.

46. Sepilian V, Nagamani M. Effects of rosiglitazone in obese women with polycystic ovary syndrome and severe insulin resistance. J Clin Endocrinol Metab 2005;90:60-5.

47. Tolman KG. The safety of thiazolidinediones. Expert Opin Drug Saf 2011;10:419-28.

48. Schernthaner G, Chilton RJ. Cardiovascular risk and thiazolidinediones-what do meta-analyses really tell us? Diabetes Obes Metab 2010;12:1023-35.

49. Saryusz-Wolska M, Szymanska-Garbacz E, Jablkowski M, Bialkowska J, Pawlowski M, Kwiecinska E, et al. Rosiglitazone treatment in nondiabetic subjects with nonalcoholic fatty liver disease. Pol Arch Med Wewn 2011;121:61-6.

50. Yee MS, Pavitt DV, Dhanjil S, Godsland IF, Richmond W, Johnston DG. The effects of rosiglitazone on atherosclerotic progression in patients with type 2 diabetes at high cardiovascular risk. Diabet Med 2010;27:1392-400.

51. Gerstein HC, Ratner RE, Cannon CP, Serruys PW, Garcia-Garcia HM, van Es GA, et al. Effect of rosiglitazone on progression of coronary atherosclerosis in patients with type 2 diabetes mellitus and coronary artery disease: the assessment on the prevention of progression by rosiglitazone on atherosclerosis in diabetes patients with cardiovascular history trial. Circulation 2010;121:1176-87. 